\title{
Review
}

\section{Laboratory animals as surrogate models of human obesity}

\author{
Cecilia NILSSON ${ }^{1}$, Kirsten RAUN ${ }^{1}$, Fei-fei YAN² ${ }^{2}$ Marianne O LARSEN ${ }^{2}$, Mads TANG-CHRISTENSEN ${ }^{1, *}$ \\ ${ }^{1}$ Diabetes Research Unit, Novo Nordisk A/S and ${ }^{2}$ Diabetes Research China, Beijing Novo Nordisk Pharmaceuticals Sci \& Tech Co Ltd, \\ Beijing 100020, China
}

\begin{abstract}
Obesity and obesity-related metabolic diseases represent a growing socioeconomic problem throughout the world. Great emphasis has been put on establishing treatments for this condition, including pharmacological intervention. However, there are many obstacles and pitfalls in the development process from pre-clinical research to the pharmacy counter, and there is no certainty that what has been observed pre-clinically will translate into an improvement in human health. Hence, it is important to test potential new drugs in a valid translational model early in their development. In the current mini-review, a number of monogenetic and polygenic models of obesity will be discussed in view of their translational character.
\end{abstract}

Keywords: obesity; animal models; sibutramine; liraglutide; KK-A $\mathrm{A}^{\mathrm{y}}$ mice; ob/ob mice; Zucker rat; diet-induced obesity models

Acta Pharmacologica Sinica (2012) 33: 173-181; doi: 10.1038/aps.2011.203

\section{Introduction}

As the prevalence of obesity is rising along with its socioeconomic consequences, the quest to find new treatments or a cure is also increasing (http://www.who.int/mediacentre/ factsheets/fs311/en/). Pharmaceutical treatment is one avenue that has been pursued, but currently there are only a limited number of compounds on the market because many have failed or been withdrawn because of side effects. Given that the development process from initial idea to marketed product typically requires more than 10 years and the attrition rate is notably high, it is important that the models used, whether in vitro or in vivo, are good surrogates for human obesity. Depending on the target in question, there are a number of models that can be applied. In the following pages, we will review the most widely used animal models in obesity research. We have categorized the different models into groups; rodent models are divided into monogenetic, polygenetic, and selectively bred diet-induced obesity (DIO) models, and finally we discuss the DIO pig model. To demonstrate the translational potential of the selected models, we have chosen two different model compound families that have been tested in human cohorts - sibutramine and liraglutide or other glucagon-like peptide-1 (GLP)-1 analogues ${ }^{[1,2]}$. Sibutramine is a serotonin and norepinephrine re-uptake inhibitor that was

\footnotetext{
* To whom correspondence should be addressed.

E-mail MDTC@novonordisk.com

Received 2011-11-17 Accepted 2011-12-21
}

developed for the treatment of obesity and has been on the market for the past 9 years, although in most markets it has been withdrawn because of undesirable side effects ${ }^{[3]}$. Liraglutide is a GLP-1 analogue currently in phase 3 clinical development for severe obesity after demonstrating positive results in phase 2 trials $^{[2]}$. By choosing the best suited animal model for a particular study, it is possible to make a qualified assessment as to whether target $X$ and/or compound $Y$ will have an impact in clinical practice at a much earlier point.

\section{Monogenic models \\ KK-A ${ }^{y}$ mice}

The inbred mouse strain KK was established in Japan and is a mouse model with peripheral insulin sensitivity and glucose intolerance $^{[4]}$. Insulin resistance in the KK mouse is followed by moderate obesity ${ }^{[5,6]}$. The occurrence of diabetes and obesity in KK mice is considered of polygenic origin. However, when the Agouti $\left(\mathrm{A}^{\mathrm{y}}\right)$ mutation is introduced into the $\mathrm{KK}$ strain, the resulting $\mathrm{KK}-\mathrm{A}^{\mathrm{y}}$ mouse exhibits a more pronounced course of diabetes ${ }^{[7,8]}$. The $\mathrm{A}^{\mathrm{y}}$ gene is ubiquitously expressed in the $\mathrm{KK}-\mathrm{A}^{\mathrm{y}}$ mouse, and the agouti protein is thought to act as a melanocortin 4 receptor antagonist, thereby inhibiting the signals from alpha-melanocyte stimulating hormone (a-MSH) and affecting the regulation of energy balance ${ }^{[9,10]}$. Thus, KK- $\mathrm{A}^{\mathrm{y}}$ can be considered a mouse with a monogenic defect but in a polygenic background that results in a predisposition for obesity.

The body weight of $\mathrm{KK}-\mathrm{A}^{\mathrm{y}}$ mice usually reaches approxi- 
mately $45 \mathrm{~g}$ at two months of age, which is characterized as moderate obesity. The body weight stabilizes by $4-5$ months of age at approximately $50-60 \mathrm{~g}$, with fat composing approximately $33 \%$ of the total body weight. Because obesity is partially caused by hyperphagia, food restriction seems effective in reversing obesity. The diabetes phenotype of KK- $\mathrm{A}^{\mathrm{y}}$ mice exhibits as hyperglycemia, hyperinsulinemia, and glucose intolerance, although hyperglycemia declines after 1 year of age. In addition, an elevated pituitary growth hormone level in combination with glycosuria caused by glomerular lesions is often observed in this animal model ${ }^{[11-13]}$.

The development of obesity and diabetes in KK-A $\mathrm{A}^{\mathrm{y}}$ mice has similarities to the development of human obesity and diabetes, and the strain has also been used in the early development of new experimental therapies. For instance, sibutramine has been tested in KK-A $\mathrm{A}^{\mathrm{y}}$ mice. Sibutramine acts to suppress calori intake and increase energy expenditure. Weight loss after sibutramine treatment has been shown in both humans and rodents ${ }^{[14,15]}$. In $\mathrm{KK}-\mathrm{A}^{\mathrm{y}}$ mice, sibutramine treatment leads to a reduction in food intake; however, the sensitivity to sibutramine was less pronounced than in wild-type mice ${ }^{[16]}$. The weight-reducing properties of GLP-1 analogues have not, to the best of our knowledge, been tested in KK-A ${ }^{\mathrm{y}}$ mice. However, exendin-4, a GLP-1 receptor agonist, increases insulin secretion and reduces glucose levels in KK-Ay mice ${ }^{[17,18]}$.

\section{$\mathrm{Ob} / \mathrm{ob}$ mouse as a model in obesity research}

The $o b / o b$ mouse is a monogenic model of obesity and diabetes due to a lack of leptin production. This mouse has been studied in many respects and is a commonly used model in obesity and diabetes research. The $d b / d b$ mouse, which in many aspects resembles the $o b / o b$ mouse, carries mutations in the leptin receptor and is usually found on the C57BLKS/J background $^{[19]}$. This mouse is a model of more severe hyperglycemia and diabetes and will not be discussed in the present review.

The $o b / o b$ phenotype was first discovered in mice in the Jackson Laboratory in $1949^{[20]}$ and was crossed back to the C57Bl/6J background. The background of the metabolic phenotype was investigated by parabiosis studies with $o b / o b$ mice and normal mice, which showed that the $o b / o b$ mice exhibited reduced food intake and body weight to become phenotypically normal and led to the proposal that $o b / o b$ mice lack a humoral satiety factor but still maintain sensitivity to this factor ${ }^{[21]}$. Based on these observations, considerable effort was put into finding this factor, which led to the positional cloning of leptin in $1994^{[22]}$. Furthermore, leptin was shown to be expressed in adipocytes, displayed increased levels in the obese and was reduced by starvation. Leptin mRNA is highly expressed in $o b / o b$ mice, but the protein is not found in the plasma of these mice ${ }^{[23]}$.

The $o b / o b$ mutation in the C57Bl/6J background results in a phenotype with marked obesity, hyperinsulinemia, insulin resistance and relatively mild hyperglycemia. In contrast, the $o b / o b$ mutation on the C57BKS background gives rise to the same phenotype as seen in $d b / d b$ mice with the C57BKS background ${ }^{[24]}$. The identity of the genetic differences contributing to the different phenotypes is not well understood, but this observation underlines the importance of the background strain when considering mouse models of obesity and diabetes. Several colonies of $o b / o b$ mice exist worldwide, each showing variations of the phenotype associated with the $o b / o b$ mutation ${ }^{[25]}$.

Obesity is the first observable phenotypic characteristic of the $o b / o b$ mouse, whereas insulin resistance and hyperglycemia follow the development of obesity. Apart from increased energy intake, even on a chow diet, obesity is further increased in $o b / o b$ mice because of a defect in thermogenesis in brown adipose tissue and therefore a larger deposition of ingested energy as $\mathrm{fat}^{[26,27]}$. Furthermore, lipogenesis, especially hepatic, is enhanced in $o b / o b$ mice, which also adds to the disposition for an obese phenotype ${ }^{[28]}$.

Islet function has been extensively studied in the $o b / o b$ mouse, displaying a large capacity for islet growth that results in hyperplasia and a large capacity for insulin secretion ${ }^{[29]}$. Based on these characteristics, the $o b / o b$ mouse has been widely used for studies on insulin secretion in the prediabetic state and as a model of beta-cell stress and proliferation. For more detailed reviews of the phenotypic characteristics of the $o b / o b$ mouse, see Lindström ${ }^{[30]}$ and Chua et $a l^{[31]}$.

Treatment with recombinant leptin in $o b / o b$ mice results in an acute reduction of food intake and increase in glucose turnover with increased glucose uptake in brown adipose tissue and the brain, whereas chronic treatment dose-dependently reduces food intake and body weight and also results in an improvement in insulin sensitivity ${ }^{[32-34]}$. In humans with leptin deficiency, recombinant leptin administration has been shown to have the same profound effects on food intake and body weight as seen in $o b / o b$ mice $^{[35]}$. However, most obese humans do not have leptin deficiency; instead, they have hyperleptinemia and leptin resistance and thus generally do not respond with weight loss during recombinant leptin treatment. This finding underlines the fact that although the $o b / o b$ mouse is indeed a valuable and useful animal model of obesity, it does not reflect the complete background of obesity in humans based on its monogenic cause of obesity and will therefore not always be predictive of the effects of pharmaceutical treatments in humans.

Treatment with sibutramine for 6 weeks in 6 week old $o b / o b$ mice has been shown to reduce weight gain by $12 \%$, but not to induce weight loss ${ }^{[36]}$. Because $o b / o b$ mice are still growing at 6 weeks of age and thus do not have a stable body weight, it is not surprising that they did not lose weight in this study. However, this observation underlines the importance of choosing a model with a stable body weight if weight loss is the desired outcome of a study. Sibutramine treatment did not have a significant effect on food intake, but it did stop the increase in plasma nonesterified fatty acids (NEFA). Furthermore, the compound induced a decrease in plasma insulin and improved insulin sensitivity compared to vehicle-treated animals ${ }^{[36]}$. Treatment with sibutramine in humans usually results in a weight loss of approximately $8 \%$ and beneficial 
effects on NEFA levels ${ }^{[1]}$. An acute study in $o b / o b$ mice showed a dose-dependent reduction of food intake and body weight in this model during the first day after receiving liraglutide. However, 2 weeks of treatment with liraglutide at a dose of $100 \mu \mathrm{g} / \mathrm{kg}$ BID did not show significant effects on body weight in ob/ob mice, although effects on blood glucose levels were seen in this model ${ }^{[37]}$.

Similarly, 2 weeks of exendin- 4 treatment in $o b / o b$ mice did not significantly affect body weight or food intake ${ }^{[38]}$. As was seen with sibutramine, another study with exendin-4 (10 or 20 $\mu \mathrm{g} / \mathrm{kg}$ BID for 8 weeks) showed a dose-dependent reduction $(20 \%-40 \%)$ of weight gain in the $o b / o b$ model $^{[39]}$. One explanation for the lack of effect on body weight in the study by Irvin et al could be that exendin- 4 was only given once daily. Conversely, the study by Ding et al demonstrated an effect of a lower daily amount of exenatide, a synthetic form of exendin-4, indicating that other factors, such as the strain of $o b / o b$ mice, could also contribute to the different results.

The lack of a consistent effect on body weight after GLP-1 receptor agonist treatment is in contrast to the robust weight loss that has been seen in humans after treatment with these compounds ${ }^{[40,41]}$, as well as to other animal models that are not monogenetic in origin.

\section{The Zucker rat}

The Zucker rat is a commonly used obese rat model. In 1961, it was discovered by TF ZUCKER and LM ZUCKER that an autosomal recessive mutation in the fatty gene $(f a)$ resulted in the obesity seen in the Zucker rat. The homozygotes for the mutation $(f a / f a)$ develop early onset obesity because of a defective leptin receptor ${ }^{[42]}$. The Zucker obese rat is hyperphagic and has reduced energy expenditure, leading to development of pronounced obesity at an early stage in life ${ }^{[43]}$. Under normal conditions, leptin produced from adipose tissue signals acts via the leptin receptor to reduce food intake. In the obese Zucker rat, this regulatory path is nonfunctional, and despite high levels of circulating leptin, the rats remain hyperphagic. Other orexigenic peptides, such as neuropeptide $\mathrm{Y}$, galanin, orexin and melanin concentrating hormone $(\mathrm{MCH})$, are also upregulated in the Zucker rat ${ }^{[44]}$. There is a preferential deposition of lipids in adipose tissue, and by 14 weeks of age, the Zucker rat has a fat percentage of $40 \%{ }^{[45,46]}$. Zucker rats develop insulin resistance in addition to obesity, but glycemic levels remain normal, and they do not develop overt diabetes $^{[47]}$. In this aspect, the Zucker rat shares similarities with a large portion of the obese human population, the group who are both obese and insulin resistant but are not diabetic. The Zucker rat is therefore considered a good animal model for this metabolic syndrome.

The effect of sibutramine on food intake has also been examined in the Zucker rat. It was found that in lean Zucker rats, which are not homozygous for the fa mutation, sibutramine resulted in a significant reduction in food intake compared to the vehicle. In obese Zucker rats, this effect was totally absent at the dose tested $(10 \mathrm{mg} / \mathrm{kg})^{[16]}$. This finding is not in accordance with the effects of sibutramine seen in human clinical studies $^{[1]}$. Thus, even if the obese Zucker rat is an animal model with several similarities to human obesity and metabolic syndrome, a discrepancy exists with respect to the pharmacological effect of sibutramine. For another class of pharmacological agents, the GLP-1 receptor agonists, the obese Zucker rat has been shown to be more predictive of the human situation with respect to regulation of appetite and body weight. Subchronic treatment of the obese Zucker rat with exendin-4 led to decreased fat deposition, reduced appetite and a reduction in weight gain ${ }^{[48]}$. Similarly, in humans, treatment with GLP-1 analogues leads to appetite reduction and weight loss ${ }^{[40,41]}$.

In a colony of outbred Zucker rats, a mutation rendering the diabetic rat was detected, which led to the development of the substrain Zucker Diabetic Fatty (ZDF) rat. Males more frequently show the diabetic phenotype than do the females. The females can develop diabetes if fed a high fat diet. However, the rate of diabetes development in males also depends on the diet ${ }^{[49]}$. The ZDF rat, especially the male, is widely used as an animal model for studies of anti-diabetic and antiobesity drugs ${ }^{[50]}$. For example, liraglutide markedly attenuated the progress of diabetes in ZDF rats. Blood glucose was significantly reduced, and plasma insulin was 2-3-fold higher during a normal 24-h feeding period compared to vehicle-only treatment. Judged by pair feeding, approximately $53 \%$ of the anti-hyperglycemic effect was mediated by a reduction of food intake.

\section{Polygenic models}

\section{Diet-induced obese rats and mice}

Monogenic animal models of obesity are useful because the obesity and adiposity they develop is often severe, resulting in a distinct phenotype. Having a distinct phenotype might be of importance for certain aspects of obesity research. Furthermore, for pharmacological treatment, a clear phenotype with a large window for drugs to exert their effects is considered beneficial.

However, a common argument against the monogenic models in general and the monogenic models deficient in the leptin system in particular is that they are not representative of the human pathogenesis of obesity. Notably few cases of human obesity can be accounted for mutations in leptin or the leptin receptor $^{[51]}$. The diet-induced obese (DIO) rat and mouse offer more human-like models, where the obesity is based on several factors, including an excess intake of calories. However, diet-induced obesity in rodents can be obtained by different means; there is a large variation both with respect to the content of the diet used, as well as the strain used.

In mice, C57B16/J is generally considered an obesity-prone strain in which pronounced weight gain, as well as hyperinsulinemia and sometimes also hyperglycemia is seen. This strain is also the most commonly used mouse strain for diet-induced obesity. A/J mice, on the other hand, are considered obesity resistant ${ }^{[52]}$. For a more elaborate examination of the obesity propensity of different mice strains, see the work by West et $a l^{[53,54]}$. There are also rat strains that are considered resistant 
to high fat diet-induced obesity, such as S5B/PI and Lou/C, whereas others develop diet-induced obesity, such as Wistar, Sprague-Dawley, Long Evans and Osborne Mendel rats ${ }^{[5]}$. Thus, it is clear that the genetic background is of major importance for the body weight response to a high-fat diet.

The modern diet, especially in West, contains high levels of fat and carbohydrates such as fructose and sucrose. Different predefined mouse and rat diets for obesity induction can vary in the percentage of calories from fat and carbohydrates, as well as the source of fat or carbohydrates, all of which can result in minor differences in phenotypes.

For a diet containing $42 \%$ of the energy as fat, the source of fat (lard, olive oil, coconut oil or fish oil) has been shown to result in differential effects on body weight gain and glucose homeostasis in male Wistar rats ${ }^{[56]}$. The authors showed that the most pronounced manifestations of obesity and insulin resistance are seen when the fat source is lard (which contains comparable quantities of saturated fat and monounsaturated fat) or olive oil (monounsaturated fat) compared to coconut oil, fish oil or a chow diet. The relatively beneficial effect of fish oil (polyunsaturated fatty acids) on lipid and glucose homeostasis compared to other fat sources has been shown previously ${ }^{[57-59]}$. However, the observation that coconut oil, which contains saturated fatty acids, is less deleterious than lard and olive oil has not been corroborated in the literature. There are actually studies suggesting that diets containing more saturated fat are obesogenic and prone to inducing insulin resistance ${ }^{[60,61]}$. It has been suggested that the response of the major hypothalamic neuropeptides regulating energy balance varies depending on the type of fat in the diet ${ }^{[60]}$.

A diet high in fat and carbohydrates, either from fructose or sucrose, closely mimics the human diet. A high-fat and highsucrose diet has been reported to result in a similar effect on body weight, abdominal fat, hyperinsulinemia and hyperglycemia as a high-fat-only diet in mice ${ }^{[52,62]}$. In recent years, the role of fructose in the development of adiposity and metabolic syndrome has received significant attention ${ }^{[63]}$. In rodents, a high-fat and high-fructose diet has been shown to result in metabolic syndrome with obesity and changed body composition $^{[64,65]}$. In a study by Shapiro et al, it was shown that feeding SD rat with fructose caused leptin resistance, which led to an exacerbated weight gain when also given a high-fat diet, suggesting that fructose increases the propensity for obesity development ${ }^{[66]}$.

Commonly used diets when inducing obesity are the $45 \%$ and $60 \% \mathrm{kcal}$ energy from fat diet (D12451 and D12492, Research Diet), where the fat source is soybean oil and lard, and the difference between the two diets is the lard content. The pharmacological treatment of DIO rodents with anti-obesity agents, such as sibutramine and liraglutide, has been shown to have effects comparable to those reported in humans. Sibutramine reduces food intake, but there are conflicting data as to whether sibutramine has an effect on energy expenditure ${ }^{[67]}$. In DIO rats, sibutramine has also been shown to reduce body weight compared to placebo $(9 \%)$ because of a reduction in food intake. This reduction was accompanied by a reduction in body fat ${ }^{[2]}$. A similar effect with a reduction in food intake and body weight for the GLP1 receptor agonists liraglutide and exendin- 4 has also been established in DIO rats fed the $60 \%$ HF diet from Research Diet ${ }^{[68]}$. Also, in DIO mice fed a diet containing $45 \%$ calories from fat, liraglutide reduces energy intake and body fat ${ }^{[69]}$. Thus, diet-induced obese rodents can be considered a valid animal model that reflects the effects seen in humans during pharmacological treatment that affects appetite and thereby reduces body weight. With respect to the effect on obesity of agents that reduce body weight, the diet used is not of crucial importance as long as proper obesity is induced by the diet of choice. However, the extent to which the different diets are comparable with respect to the secondary outcomes of obesity medications, such as plasma lipids and glucose tolerance, needs to be further explored.

\section{Cafeteria diet-induced obesity}

Obesity in rats can also be induced with less standardized and predefined diets, such as the Cafeteria Diet, which means that the animals have a choice of various palatable energydense food items as an alternative to standard chow ${ }^{[7,71]}$. The advantage to this approach is that the diet is palatable and the propensity to overeat is larger than that for a standardized, predefined high-fat diet. Furthermore, it is more similar to the human diet situation. However, the diet is criticized for being difficult to standardize with respect to nutritional content, and the animals might experience deficiencies in proteins or essential vitamins ${ }^{[72]}$. The model has not been as widely used for the development of obesity treatment as the DIO rat described above. At Novo Nordisk, we have employed a Cafeteria Diet DIO rat model in which the rats were fed chow ad libitum and were offered up to $20 \mathrm{~g}$ of candy per day. The candy was provided on a rotational basis and included chocolate biscuits, other kinds of chocolate and grape sugar to maximize the interest in the candy and to tempt the rat to eat more. Seventy-five percent of the calories were provided by candy intake because the DIO rat preferred candy over chow. This preference led to a $15 \%-20 \%$ higher weight gain in DIO rats than in chow-fed rats, which was attributable to an increase in fat mass ${ }^{[73]}$. Treatment with liraglutide, but not with vildagliptin, resulted in a significant reduction in body weight. Liraglutide, but not vildagliptin, reduced the total caloric intake. Interestingly, it also seemed to change food preference because a preferential reduction in candy intake and a relative increase in chow intake were seen after liraglutide treatment in candyfed rats ${ }^{[73]}$.

\section{DIO-DR}

Three decades ago, Dr Levin and co-workers refined the DIO model by selectively breeding Sprague Dawley (SD) rats for obesity $^{[74]}$. Dr Levin took 100 normal SPD rats and subjected them to a high-fat diet (60\% calories from fat). After several weeks on the diet, the animals could be divided into the following three groups: a low, middle and high BW group. Thereafter, the researchers mated rats that had increased their 
body weight by a small or large amount in subsequent generations until total segregation was achieved, and the researchers started an out-breeding program. The individual groups were named diet resistant (DR) or obesity prone (DIO) ${ }^{[74]}$. The advantage of this process was that it was clear from the pup stage they could be absolutely sure that the pups from the DIO group would gain more weight and pups from the DR group would gain less weight when exposed to a high-fat diet. The increase in BW was predominantly caused by a general increase in fat mass and, to a much lesser extent, muscle mass, making the DIO rat a true diet-induced obese rat and not simply a "large" rat. Over approximately the past decade, Dr Levin, academic colleagues, and the biotech and pharmaceutical industry throughout the world have applied this model in target discovery and also as an important benchmark model ${ }^{[75-77]}$. The obesity in the DIO rat is not caused by a single gene but rather is truly polygenetic in nature. After 14-16 weeks on a high-fat diet $(60 \%$ calories from fat, provided by Research diet) the metabolic parameters of the DIO rats reflect the altered diet with an increase in TG, insulin and lipids, which mirrors the human condition known as metabolic syndrome, making this model truly translational ${ }^{[75]}$. The model has shown its value already, as all approved drugs that have a marked effect on BW in humans have been shown to have a similar effect in the DIO rat. Sibutramine po for 3 weeks leads to a weight reduction of approximately $10 \%-13 \%$ of basal weight in this model, which is slightly more than what has been seen in clinical experiments. With respect to liraglutide, the weight loss in rats is approximately $10 \%$, which is slightly more $(12 \%)^{[75]}$ than has been seen in 1-year liraglutide trials performed by Dr Astrup ${ }^{[2]}$.

\section{UCD-T2DM rat}

One of the drawbacks of the DIO rodent models is that they develop hyperinsulinemia but not always hyperglycemia, thereby making them good models for obesity but not necessarily for type 2 diabetes. Havel and co-workers ${ }^{[78]}$ have developed a polygenic rat model with adult-onset obesity, insulin resistance and late onset type 2 diabetes that maintains leptin signaling without dietary intervention. The model originates from crossing obese, insulin-resistant SD rats with lean ZDF rats.

Thus, the model is a cross between a model employing obesity and insulin resistance but with $\beta$-cells robust enough not to develop diabetes and a model with a $\beta$-cell defect that does not develop diabetes when insulin sensitivity is normal. By the F7 generation, it appeared that all animals were homozygous for the $\beta$-cell defect ${ }^{[79]}$, and both sexes develop diabetes at $183 \pm 10$ and $286 \pm 17$ days of age, respectively (the incidence is $91.9 \%$ for males and $42.6 \%$ for females). The body weight and caloric intake are significantly higher for the UC Davis type 2 diabetes mellitus rat [UCD (University of California Davis)-T2DM] than the lean SD rat. The increased obesity and hyperphagia precede the onset of diabetes, and after the onset of diabetes, a slow loss of body weight is seen. Furthermore, early body weight has a significant influence on the age of onset of diabetes, which is consistent with the reported increased risk for T2DM with obesity. The UCD-T2DM rat is well suited for studies of pharmacological prevention of T2DM. Liraglutide has been tested for its ability to reduce body weight, as well as to prevent or delay the onset of diabetes in UCD-T2DM rats $(0.2 \mathrm{mg} / \mathrm{kg})^{[80]}$. This study included a group that was weight matched to the liraglutide group. This group was restricted to a food intake of $9 \%$ less energy $/ \mathrm{kg}$ body weight than the animals that received liraglutide. The requirement of a $9 \%$ reduction in energy intake as compared to treatment with liraglutide to obtain similar weight suggests a beneficial component of liraglutide treatment on energy expenditure. The energy intake after liraglutide treatment was significantly reduced compared to vehicle-treated animals. Both liraglutide treatment and food restriction significantly delayed the onset of diabetes in the UCD-T2DM rat. However, liraglutide markedly lowered fasted plasma insulin compared to food-restricted rats, suggesting that improved insulin sensitivity was not caused by the effect on body weight alone. The large effect on the delay of the onset of diabetes after food restriction suggests that part of the beneficial effects of liraglutide is mediated via a reduction in energy intake and body weight. Furthermore, despite having a similar body weight, the liraglutide-treated animals had an even more pronounced reduction in body adiposity than did weight-matched animals. $\mathrm{NZO}$ and NoncNZO mouse

The New Zealand obese (NZO) mouse is a polygenic model that develops hyperphagia and juvenile onset obesity, even when fed a low fat diet. Both subcutaneous and visceral fat is accumulated. Furthermore, the mouse develops type 2 diabetes, although at varying frequencies depending on substrain and gender ${ }^{[81,82]}$.

The NZO mice have been crossed with the nonobese nondiabetic (NON) mouse, which has impaired glucose tolerance and impaired $\beta$-cell insulin secretion capacity but still do not develop overt diabetes. The NONcNZO10/LtJ strain is a result of several crossings between NZO and NON mice. Both female and male NONcNZO10/LTJ mice develop obesity, but only males develop type 2 diabetes ${ }^{[83]}$. The disease inheritance of NONcNZO10/LtJ reflects the complex inheritance pattern of human obesity.

The NZO mice and the NONcNZO10/LtJ mice have primarily been used for pharmacogenetic studies. However, there are reports of pharmacology studies. For example, it has been shown that a $\beta_{3}$-adrenergic receptor agonist (CL316, 243) lowers body weight in these mice while increasing food intake and suppressing the development of diabetes in the mice ${ }^{[84]}$. Furthermore, rosiglitazone treatment leads to a body weight increase in NONcNZO/LtJ mice and in humans ${ }^{[84,85]}$. The utility of the two models in pharmacological obesity studies as well as their predictivity in humans remains to be verified.

\section{Tallyho mouse}

The Tallyho mouse is also a model with moderate obesity and male-derived hyperglycemia with a polygenic origin ${ }^{[86]}$. A recent publication suggests that increased food intake, not 
reduced energy expenditure, is the reason for the obesity in Tallyho mice as compared to C57BL6/J mice. When pair fed with C57B16/J mice, the Tallyho mice have the same rate of weight gain as the C57B16/J mice. Furthermore, the authors show that Tallyho mice have hypothalamic leptin resistance and upregulation of NPY mRNA levels ${ }^{[87]}$. There are, to the best of our knowledge, no publications in which Tallyho mice have been used in the pharmacological treatment of obesity; therefore, their utility and predictivity for human obesity treatment is unclear.

\section{DIO minipigs}

The obese Göttingen minipig is a relatively novel model; therefore, there are few reports on its metabolic status, as well as limited reports of pharmacological intervention studies.

Adult Göttingen minipigs have a body weight of 30 to 35 $\mathrm{kg}$, and food restriction is necessary to maintain a lean phenotype. When fed ad libitum with normal pig chow, females have a food intake that is more than double that of the agespecific norms for this breed based on a restricted diet ${ }^{[88]}$. This increased food intake leads to massive obesity, and by 18 months of age, the pigs are two to three times the weight of animals fed restricted amounts of fat with percentage close to $50 \%$ because of their hyperphagic behavior. Thus, without food restriction, this model seems to have a normal development toward severe obesity. The hyperphagic element of this obesity seems similar to the food cravings observed in severely overweight humans, in contrast to the polygenic DIO rodent model, which shows moderate obesity and body fat. The degree of obesity measured by body weight, as well as excess body fat seen in the DIO pig model, closely resembles human obesity. However, one should be aware that the model is not well characterized, and although the obese minipigs become insulin resistant, similar to obese humans, they do not develop type 2 diabetes. Also, this model is resource intensive with respect to space, time and the quantity of compounds needed for studies.

In a pharmacological intervention study ${ }^{[89]}$ with liraglutide, the effect on body weight loss was of the same magnitude as has been shown in human clinical obesity studies with this compound $^{[2]}$. Six female Göttingen minipigs (Ellegaard Göt- tingen Minipigs, Dalmose, Denmark) aged approximately 18 months of age and with a mean body weight of $90.3 \pm 6.0 \mathrm{~kg}$ at the beginning of the study were used in this experiment. The minipigs had been fed ad libitum since weaning and this continued throughout the study.

Food intake was monitored continuously throughout the study, and body weight was determined twice weekly using a standard large-animal scale. In this three-period experiment (baseline, treatment and posttreatment follow-up), each animal was used as its own control. Liraglutide profoundly affected food intake with an overall reduction of $60 \%$ for the 7 -week treatment period without any signs of desensitization. This approach meant that food intake came close to the level required for maintenance of normal body weight in these pigs. Food intake returned to pre-treatment levels within 4 days of termination of liraglutide treatment and, although variable, remained within the pre-treatment range for the remainder of the study. The effect on body weight was a reduction of $4.3 \pm 1.2 \mathrm{~kg}$ compared to a $7.0 \pm 1.0 \mathrm{~kg}$ weight gain during the 7 week pre- and post-treatment periods. The DIO Göttingen minipig model seems to resemble human obesity and also responds to a similar degree to obesity intervention treatment with liraglutide.

\section{Conclusion}

As described, there are a number of valid surrogate animal models of human obesity that can be utilized in the discovery and developmental process. An overview of the different models in this review is found in Table 1. That these models have translational character is evident from the data we have presented on sibutramine and liraglutide, although the number of models described is far from exhaustive. However, the human obesity phenotype is, for the majority of people, caused by the interplay between a long list of genes and the environment; therefore, the laboratory animal model that best reflects this is polygenetic dietary-induced models. The monogenetic models do have a role in terms of teasing out the mechanism and mode of action of these diseases, but the best surrogate models are the DIO. Over the past few years, a number of models using dietary manipulations (high-fructose/high-carbohydrate) have emerged, but they are left out of the current

Table 1. An overview of the different models of obesity.

\begin{tabular}{|c|c|c|c|c|c|c|}
\hline & $K K-A^{y}$ & $O b / o b$ & Zucker & $\begin{array}{l}\text { DIO or Cafeteria } \\
\text { diet or DIO DR }\end{array}$ & UCD-T2M & DIO minipig \\
\hline Cause of disease & $\begin{array}{c}\text { Monogenic }\left(A^{y}\right) \text { and } \\
\text { polygenic }(K K)\end{array}$ & Monogenic & Monogenic & $\begin{array}{l}\text { Induced and } \\
\text { polygenic }\end{array}$ & Polygenic & Induced \\
\hline Obesity & Yes & Yes & Yes & Yes & Yes & Yes \\
\hline Hyperphagia & Yes & Yes & Yes & No & Yes & Yes \\
\hline Hyperglycemia & Yes & Mild & No & No & Yes & No \\
\hline Weight reducing effect of sibutramine & Marginal & Marginal & No & Yes & $?$ & $?$ \\
\hline Weight reducing effect of GLP1 analogues & $?$ & None or marginal & Yes & Yes & Marginal & Yes \\
\hline
\end{tabular}


review because further testing is required to validate these models. It is likely that these models will potentially lead to a model that is even more predictive of the human disease, leaving us with a more optimized tool that will potentially reduce the path to market and will eliminate the necessity of a number of animal studies.

\section{Acknowledgements}

The authors thank Senior Scientist Lotte Bjerre KNUDSEN for helpful discussion of the manuscript and Annette THYDE for excellent administrative and technical assistance.

\section{References}

1 Padwal RS, Jajumdar SR. Drug treatments for obesity; orlistat sibutramine and rimonabant. Lancet 2007; 369: 71-7.

2 Astrup A, Rössner S, Van Gaal L, Rissanen A, Niskanen L, Al Hakim M, et al. Effects of liraglutide in the treatment of obesity: a randomised, double-blind, placebo-controlled study. Lancet 2009; 374: 1606-16.

3 Finer $\mathrm{N}$. Executive steering committee of the sibutramine cardiovascular outcome trial. Withdrawal of sibutramine. Editorial is judgement in advance of the facts. BMJ 2010; 340: C1346.

4 Kondo K, Nozawa K, Tomira T, Ezaki K. Inbred strains resulting from Japanese mice. Bull Exp Anim 1957; 6: 107-12.

5 Igel M, Taylor BA, Phillips SJ, Becker W, Herberg L, Joost HG. Hyperleptinemia and leptin receptor variant Asp600Asn in the obese, hyperinsulinemic KK mouse strain. J Mol Endocrinol 1998; 21: 337-45.

6 Ikeda H. KK mouse. Diabetes Res Clin Practice 1994; 24: S313S316.

7 Nishimura. Breeding of mice strains for diabetes mellitus. Exp Animals 1969; 18: 147-57.

8 Iwatsuka H, Shino A, Suzuoki Z. General survey of diabetic features of yellow KK mice. Endocrinology 1970; 17: 23-35.

9 Klebig ML, Wilkinson JE, Geisler JG. Ectopic expression of the agouti gene in transgenic mice causes obesity, features of type II diabetes, and yellow fur. Proc Natl Acad Sci U S A 1995; 92: 4728-32.

10 Stütz AM, Morrison CD, Argyropoulus G. The agouti-related protein and its role in energy homeostasis. Peptides 2005; 26: 1771-81.

11 Bray GA, York DA. Genetically transmitted obesity in rodents. Physiol Rev 1971; 51: 598-646.

12 Butler L, Gerritsen GC. A comparison of the modes of inheritance of diabetes in the Chinese hamster and the KK mouse. Diabetologia 1970; 6: 163-7.

13 Butler $\mathrm{L}$. The inheritance of glucosuria in the $\mathrm{KK}$ and AY mouse. Can J Genet Cytol 1972; 14: 265-9.

14 Stock MJ. Sibutramine: a review of the pharmacology of a novel antiobesity agent. Int J Obes Relat Metab Disord 1997; 21 Suppl 1: S25-9.

15 Bray GA, Greenway FL. Current and potential drugs for treatment of obesity. Endocr Rev 1999; 20: 805-75.

16 Matsumoto K, lijima H. Sibutramine sensitivity assay revealed a unique phenotype of bombesin BB3 receptor-deficient mice. Eur J Pharmacol 2003; 473: 41-6.

17 Song GM, Huan Y, Sun SJ, Chen YT, Liu Q, Shen ZF. Biological activity of EXf, a peptide analogue of exendin-4. Eur J Pharmacol 2010; 628: 261-7.

18 Thorens B, Porret A, Buhler L, Deng SP, Morel P, Widman C. Cloning and functional expression of the GLP-1 receptor: demonstration that exendin-4 is an agonist and exendin $3(9-39)$ is an antagonist of the receptor. Diabetes 1993; 42: 1678-82

19 Hummel KP, Dickie MM, Coleman DL. Diabetes, a new mutation in the mouse. Science 1966; 153: 1127-8.

20 Ingalls, AM, Dickie MM, Coleman DL. Obese, a new mutation in the house mouse. J Heredity 1950; 41: 317-8.

21 Coleman DL. Effects of parabiosis of obese with diabetes and normal mice. Diabetologia 1973; 9: 294-8.

22 Zhang Y, Proenca R, Maffei M, Barone M, Leopold L, Friedman JM. Positional cloning of the mouse obese gene and its human homologue. Nature 1994; 372: 425-31.

23 Frederich RC, Lollmann B, Hamann A, Napolitano-Rosen A, Kahn BB, Lowell BB, et al. Expression of ob mRNA and its encoded protein in rodents, impact of nutrition and obesity. J Clin Invest 1995; 96 : 1658-63.

24 Coleman DL, Hummel KP. Obese gene in the mouse. Diabetologia 1973; 9: 287-93.

25 Herberg L, Coleman DL. Laboratory animals exhibiting obesity and diabetes syndromes. Metabolism 1977; 26: 59-99.

26 Trayhurn P, Jones PM, McGuckin MM, Goodbody AE. Effects of overfeeding on energy balance and brown fat thermogenesis in obese (ob/ob) mice. Nature 1982; 295: 323-5.

27 Hogan S, Himms-Hagen J. Abnormal brown adipose tissue in obese (ob/ob) mice: response to acclimation to cold. Am J Physiol 1980; 239: E301-E309.

28 Memon RA, Fuller J, Moser AH, Smith PJ, Grunfeld C, Feingold KR. Regulation of putative fatty acid transporters and Acyl-CoA synthetase in liver and adipose tissue in ob/ob mice. Diabetes 1999; 48: 121-7.

29 Lindström P. $\beta$-Cell function in obese-hyperglycemic mice [ob/ob Mice] in the islets of Langerhans, advances in experimental medicine and biology, ed: Islam MS, 2010 654: 463-477, DOI 10.1007/978-90481-3271-3_20

30 Lindström P. The physiology of obese-hyperglycemic mice [ob/ob Mice]. TheScientificWorldJOURNAL 2007; 7: 666-85.

31 Chua S, Herberg L, Leiter EH. Obesity/diabetes in mice with mutations in leptin or leptin receptor genes. In Shafrir E (ed). Animal models of Diabetes Frontiers in Research. London: Boca Raton, Fla. CRC; 2007. p 61-102.

32 Burcelin R, Kamohara S, Li J, Tannenbaum GS, Charron MJ, Friedman $J M$. Acute intravenous leptin infusion increases glucose turnover but not skeletal muscle glucose uptake in ob/ob mice. Diabetes 1999; 48: 1264-9.

33 Pelleymounter MA, Cullen MJ, Baker MB, Hecht R, Winters D, Boone T, et al. Effects of the obese gene product on body weight regulation in ob/ob mice. Science 1995; 269: 540-3.

34 Weigle DS, Bukowski TR, Foster DC, Holderman S, Kramer JM , Lasser $\mathrm{G}$, et al. Recombinant ob protein reduces feeding and body weight in the ob/ob mouse. J Clin Invest 1995; 96: 2065-70.

35 Farooqi IS, Matarese G, Lord GM, Keogh JM, Lawrence E, Agwu C, et al. Beneficial effects of leptin on obesity, $T$ cell hyporesponsiveness and neuroendocrine/metabolic dysfunction of human congenital leptin deficiency. J Clin Invest 2002; 110: 1093-103.

36 Day C, Bailey CJ. Effect of the antiobesity agent sibutramine in obesediabetic ob/ob mice. Int J Obes Relat Metab Disord 1998; 22: 61923.

37 Rolin B, Larsen MO, Gotfredsen CF, Deacon CF, Carr RD, Wilken M, et al. The long-acting GLP-1 derivative NN2211 ameliorates glycemia and increases beta-cell mass in diabetic mice. Am J Physiol Endocrinol Metab 2002; 283: E745-52.

38 Irwin N, McClean PL, Cassidy RS, O'harte FP, Green BD, Gault VA, et al. Comparison of the anti-diabetic effects of GIP- and GLP-1receptor activation in obese diabetic (ob/ob) mice: studies with DPP IV resistant N-AcGIP and exendin(1-39)amide. Diabetes Metab Res Rev 2007; 23: 572-9. 
39 Ding X, Saxena NK, Lin S, Gupta NA, Anania FA. Exendin-4, a glucagon-like protein-1 (GLP-1) receptor agonist, reverses hepatic steatosis in ob/ob mice. Hepatology 2006; 43: 173-81. Erratum in: Hepatology 2006; 44: 515.

40 Vergès B, Bonnard C, Renard E. Beyond glucose lowering: Glucagonlike peptide-1 receptor agonists, body weight and the cardiovascular system. Diabetes Metab 2011. Doi : 10.1016/j.diabet.2011.07.001.

41 Bode B. Liraglutide: a review of the first once-daily GLP-1 receptor agonist. Am J Manag Care 2011; 17: S59-70.

42 Phillips MS, Liu Q, Hammond HA, Dugan V, Hey PJ, Caskey CJ, et al. Leptin receptor missense mutation in the fatty Zucker rat. Nat Genet 1996; 13: 18-9.

43 White BD, Martin RJ. Evidence for a central mechanism of obesity in the Zucker rat: role of neuropeptide $Y$ and leptin. Proc Soc Exp Biol Med 1997; 214: 222-32.

44 Artiñano AA, Castro MM. Experimental rat models to study the metabolic syndrome. Br J Nutr 2009; 102: 1246-53.

45 Zucker TF, Zucker LM. Hereditary obesity in the rat associated with high serum fat and cholesterol. Proc Soc Exp Biol Med 1962; 110: 165-71.

46 Zucker LM, Antoniades HN. Insulin and obesity in the Zucker genetically obese rat "fatty". Endocrinology 1972; 90: 1320-30.

47 Bray GA. The Zucker-fatty rat: a review. Fed Proc 1977; 36: 148-53.

48 Szayna M, Doyle ME, Betkey JA, Holloway HW, Spencer RGS, Greig $\mathrm{NH}$, et al. Exendin-4 decelerates food intake, weight gain, and fat deposition in Zucker rats. Endocrinology 2000; 141: 1936-41.

49 Corsetti JP, Sparks JD, Peterson RG, Smith RL, Sparks CE. Effect of dietary fat on the development of non-insulin dependent diabetes mellitus in obese Zucker diabetic fatty male and female rats. Atherosclerosis 2000; 148: 231-41.

50 Clark JB, Palmer CJ, Shaw WN. The diabetic Zucker fatty rat. Proc Soc Exp Biol Med 1983; 173: 68-75.

51 Farooqi IS, Jebb SA, Langmack G, Lawrence E, Cheetham CH, Prentice $A M$, et al. Effects of recombinant leptin therapy in a child with congenital leptin deficiency. N Eng J Med 1999; 341: 879-84.

52 Surwit RS, Feinglos MN, Rodin J, Sutherland A, Petro AE, Opara EC, et al. Differential effects of fat and sucrose on the development of obesity and diabetes C57BL/6J and A/J mice. Metabolism 1995; 44: 645-51.

53 West DB, Boozer CN, Moody DL, Atkinson RL. Dietary obesity in nine inbred mouse strains. Am J Physiol 1992; 262: R1025-R1032.

54 West DB, Waguespack J, McCollister S. Dietary obesity in the mouse: interaction of strain with diet composition. Am J Physiol 1995; 268 : R658-R665.

55 Schemmel R, Mickelsen O, Motawi K. Conversion of dietary to body energy in rats as affected by strain, sex and ration. J Nutr 1972; 102: 1187-97.

56 Buettner R, Parhofer KG, Woenckhaus M, Wrede CE, Kunz-Schughart LA, Scholmerich J, et al. Defining high-fat-diet rat models: metabolic and molecular effects of different fat types. J Mol Endocrinol 2006; 36: 485-501.

57 Huang XF, Xin X, McLennan P, Storlien L. Role of fat amount and type in ameliorating diet-induced obesity: insights at the level of hypothalamic arcuate nucleus leptin receptor, neuropeptide $Y$ and pro-opiomelanocortin mRNA expression. Diabetes Obes Metab 2004; 6: 35-44.

58 Storlien LH, Higgins JA, Thomas TC, Brown MA, Wang HQ, Huang XF, et al. Diet composition and insulin action in animal models. Br J Nutr 2000; 83 Suppl 1: S85-S90.

59 Delarue J, LeFoll C, Corporeau C, Lucas D. N-3 long chain polyunsaturated fatty acids: a nutritional tool to prevent insulin resistance associated to type 2 diabetes and obesity? Reprod Nutr Dev 2004; 44: 289-99.

60 Wang H, Storlien LH, Huang XF. Effects of dietary fat types on body fatness, leptin, and ARC leptin receptor, NPY, and AgRP mRNA expression. Am J Physiol Endocrinol Metab 2002; 282: E1352-E1359.

61 Storlien LH, Jenkins AB, Chisholm DJ, Pascoe WS, Khouri S, Kraegen EW. Influence of dietary fat composition on development of insulin resistance in rats. Relationship to muscle triglyceride and omega-3 fatty acids in muscle phospholipid. Diabetes 1991; 40: 280-9.

62 Sato-Mito N, Suzui M, Yoshino H, Kaburagi T, Sato K. Long term effects of high fat and sucrose diets on obesity and lymphocyte proliferation in mice. J Nutr Health Aging 2009; 13: 602-6.

63 Bray GA. Soft drink consumption and obesity: it is all about fructose. Curr Opin Lipidol 2010; 21: 51-7.

64 Wada T, Kenmochi H, Miyashita Y, Sasaki M, Ojima M, Sasahara $\mathrm{M}$, et al. Spironolactone improves glucose and lipid metabolism by ameliorating hepatic steatosis and inflammation and suppressing enhanced gluconeogenesis induced by high-fat and high-fructose diet. Endocrinology 2010; 151: 2040-9.

65 Couturier K, Batandier C, Awada M, Hininger-Favier I, Canini F, Anderson RA, et al. Cinnamon improves insulin sensitivity and alters the body composition in an animal model of the metabolic syndrome. Arch Biochem Biophys 2010; 501: 158-61.

66 Shapiro A, Mu W, Roncal C, Cheng KY, Johnson RJ, Scarpace PJ. Fructose-induced leptin resistance exacerbates weight gain in response to subsequent high-fat feeding. Am J Physiol Regul Integr Comp Physiol 2008; 295: R1370-R1375.

67 Sharma B, Henderson DC. Sibutramine: current status as an antiobesity drug and its future perspectives. Expert Opin Pharmacother 2008; 9: 2161-73.

68 Hayes MR, Kanoski SE, Alhadeff AL, Grill HJ. Comparative effects of the long-acting GLP-1 receptor ligands, liraglutide and exendin-4, on food intake and body weight suppression in rats. Obesity 2011; 19 : 1342-9.

69 Porter DW, Kerr BD, Flatt PR, Holscher C, Gault VA. Four weeks administration of liraglutide improves memory and learning as well as glycaemic control in mice with high fat dietary-induced obesity and insulin resistance. Diabetes Obes Metab 2010; 12: 891-9.

70 Sclafani A, Springer D. Dietary obesity in adult rats: similarities to hypothalamic and human obesity syndromes. Physiol Behav 1976; 17: 461-71.

71 Rothwell NJ, Stock MJ. The cafeteria diet as a tool for studies of thermogenesis. J Nutrition 1988; 118: 925-8

72 Moore BJ. The cafeteria diet-an inappropriate tool for studies of thermogenesis. J Nutr 1987; 117: 227-31.

73 Raun K, von Voss P, Gotfredsen CF, Golozoubova V, Rolin B, Knudsen LB. Liraglutide, a long-acting glucagon-like peptide- 1 analog, reduces body weight and food intake in obese candy-fed rats, whereas a dipeptidyl peptidase-IV inhibitor, vildagliptin, does not. Diabetes 2007; 56: 8-15.

74 Levin BE, Hogan S, Sullivan AC. Initiation and perpetuation of obesity and obesity resistance in rats. Am J Physsiol 1989; 256: R766-771.

75 Madsen AN, Hansen G, Paulsen SJ, Lykkegaard K, Tang-Christensen $\mathrm{M}$, Hansen HS, et al. Long-term characterization of the diet-induced obese and diet-resistant rat model: a polygenentic rat model mimicking the human obesity syndrome. J Endocrinol 2010; 206: 287-96.

76 Levin BE, Keesey RE. Defense of differing weight set points in diet induced obese and resistant rats. Am J Physiol 1998; 274: R412-9.

77 Levin BE, Dunn-Meynell AA, Balkan B, Keesey RE. Selective breeding for diet-induced obesity and resistance in Spraque Dawley rats. Am J 
Physiol 1997; 273; R725-R730.

78 Cummings BP, Digitale EK, Stanhope KL, Graham JL, Baskin DG, Reed BJ, Sweet IR, Griffen SC, Havel PJ. Development and characterization of a novel rat model of type 2 diabetes mellitus: the UC Davis type 2 diabetes mellitus UCD-T2DM rat. Am J Physiol Regul Integr Comp Physiol 2008; 295: R1782-93.

79 Cummings BP, Digitale EK, Stanhope KL, Graham JL, Baskin DG, Reed BJ, et al. Development and characterization of a novel rat model of type 2 diabetes mellitus: the UC Davis type 2 diabetes mellitus UCD-T2DM rat. Am J Physiol Regul Integr Comp Physiol 2008; 295: R1782-93.

80 Cummings BP, Stanhope KL, Graham JL, Baskin DG, Griffen SC, Nilsson $\mathrm{C}$, et al. Chronic administration of the glucagon-like peptide-1 analog, liraglutide, delays the onset of diabetes and lowers triglycerides in UCD-T2DM rats. Diabetes 2010; 59: 2653-61.

81 Bielschowsky M, Bielschowsky M. A new strain of mice with hereditary obesity. Proc Univ Otago Med School 1953; 31: 29-3.

82 Leiter EH, Reifsnyder PC. Differential levels of diabetogenic stress in two new mouse models of obesity and type 2 diabetes. Diabetes 2004; 53 Suppl 1: S4-11.

83 Cho YR, Kim HJ, Park SY, Ko HJ, Hong EG, Higashimori T, et al. Hyperglycemia, maturity-onset obesity, and insulin resistance in
NONcNZO10/LtJ males, a new mouse model of type 2 diabetes. Am J Physiol Endocrinol Metab 2007; 293: E327-E336.

84 Koza RA, Flurkey K, Graunke DM, Braun C, Pan HJ, Reifsnyder PC, et al. Contributions of dysregulated energy metabolism to type 2 diabetes development in NZO/H1Lt mice with polygenic obesity. Metabolism 2004; 53: 799-808.

85 Pan HJ, Reifsnyder P, Vance DE, Xiao Q, Leiter EH. Pharmacogenetic analysis of rosiglitazone-induced hepatosteatosis in new mouse models of type 2 diabetes. Diabetes 2005; 54: 1854-62.

$86 \mathrm{Kim} \mathrm{JH}$, Sen S, Avery CS, Simpson E, Chandler P, Nishina PM, et al. Genetic analysis of a new mouse model for non-insulin-dependent diabetes. Genomics 2001; 74: 273-86.

87 Rhee SD, Sung YY, Lee YS, Kim JY, Jung WH, Kim MJ, et al. Obesity of TallyHO/JngJ mouse is due to increased food intake with early development of leptin resistance. Exp Clin Endocrinol Diabetes 2011; 119: 243-51.

88 Bollen PJ, Madsen LW, Meyer O, Ritskes-Hoitinga J. Growth differences of male and female Göttingen minipigs during ad libitum feeding: a pilot study. Lab Animal 2005; 39: 80-93.

89 Raun K, von Voss P, Knudsen LB. Liraglutide, a once-daily human glucagon-like peptide-1 analog, minimizes food intake in severely obese minipigs. Obesity 2007; 15: 1710-6. 